\title{
EDITORIAL
}

\section{AFRICAN JOURNAL OF ORAL HEALTH IS MAKING PROGRESS}

It is my pleasure to welcome our readers and subscribers to the second issue of AJOH for year 2016. Although it is coming later than anticipated, this was borne out of the need to further position the journal for easier accessibility, visibility and functionality. I am quite pleased to inform our readers that manuscript processing is now fully automated and manuscripts can be submitted on the journal website http://ajoh.oauife.edu.ng/. We also warmly welcome Dr. O. K. Ogundipe to the editorial team.

This edition has a comprehensive review on implant connections, which is quite relevant especially in the developing nations. Implant dentistry is still at its infancy in many parts of Africa, however the demand for dental implants is growing due to increased awareness. Presently, only the high socioeconomic class in Nigeria can afford dental implants, hopefully in the near future the coverage should get wider.

Another article examined the satisfaction of dental patients in line with their expectations. Despite conflicting expectations from patients on what is to be done, there was still satisfaction from the treatments rendered. Majority of patients only visited the dentist due to pain. However, the few patients who attended for check-up had no idea of what it entails. The paper highlighted the need for enlightenment on dental health matters in order to build the right knowledge of dental care in the population.
A third article drew attention to a poorly recognized complication of antiretroviral therapy. The picture of HIV infection in Sub-Saharan Africa where the bulk of the epidemic lies is that of limited access to antiretroviral therapy or the use of first line antiretroviral drugs. In many HIV treatment centers, the first line drugs are still what are available given the relatively high cost of therapy. While government and non-government agencies battle to reduce poverty and improve access to more efficient antiretroviral therapy, practitioners should remain alert to the complications of HIV treatment, especially with the new "test and treat" policy of the World Health Organization (WHO).

References

1. Akeredolu PA, Adeyemo WL, Omololu OB, Karunwi O. Implant restoration of partially edentulous ridges: a review of 121 Nigerian patients. Implant Dent. $2010 ; 19(1): 65-72$.

2. Geerts G, Naidoo S. Surgical placement of implants-experiences, practices and opinions of South African prosthodontists. SADJ. 2012;67(3):108-114

3. Nansseu JR, Bigna JJ. Antiretroviral therapy related adverse effects: can sub-Saharan Africa cope with the new "test and treat" policy of the World Health Organization? Infect Dis Poverty. 2017;6(1):24. 